\title{
Duct-vented Propane/Air Explosions with Central and Rear Ignition
}

\author{
G. FERRARA ${ }^{2}$, S.K. WILLACY ${ }^{1}$, H.N. PHYLAKTOU ${ }^{1}$, G.E. ANDREWS ${ }^{1}$, \\ A. Di BENEDETTO ${ }^{2}$, and M.C. MKPADI ${ }^{1}$ \\ ${ }^{1}$ Energy and Resources Research Institute \\ University of Leeds \\ LS2 9JT, UK \\ ${ }^{2}$ University of Naples Frederico II \\ Naples, Italy
}

\begin{abstract}
It is commonplace in industrial installations to have duct vented vessels, the design of which is often based upon the premise that central ignition will provide the worst case scenario. This research investigates duct-vented explosions using a vented test chamber of $200 \mathrm{l}$ capacity fitted with a $1 \mathrm{~m}$ long vent pipe, discharging into a large $\left(50 \mathrm{~m}^{3}\right)$ dump volume with rear and central ignition. Propane-air mixtures over a range of concentrations $(\Phi=0.8-1.6)$ have been used. Results show that while there is no significant difference in maximum pressure in the test vessel for rear and central ignition, rear ignition consistently produces the worst case in terms of rates of pressure rise and flame-speeds in the duct. In addition, the detailed records of pressure traces and flame position showed a direct relationship between the induced gas velocity in the duct prior to the flame arrival and the subsequent rate of pressure rise in the vessel. The implications of the findings for practical systems are briefly discussed.
\end{abstract}

KEYWORDS: explosion, propane, vented, duct

\section{NOMENCLATURE}

$\begin{array}{ll}D & \text { Diameter (m) } \\ K & \text { Contraction coefficient } \\ L & \text { Length (m) } \\ P & \text { Pressure (barg) } \\ T & \text { Thermocouple } \\ t & \text { time (s) } \\ u & \text { Velocity of unburned gas (m/s) } \\ Y & \text { Concentration (\%vol) } \\ d p / d t & \text { Rate of pressure rise (bar/s) } \\ \Delta P & \text { Pressure Difference (bar) }\end{array}$

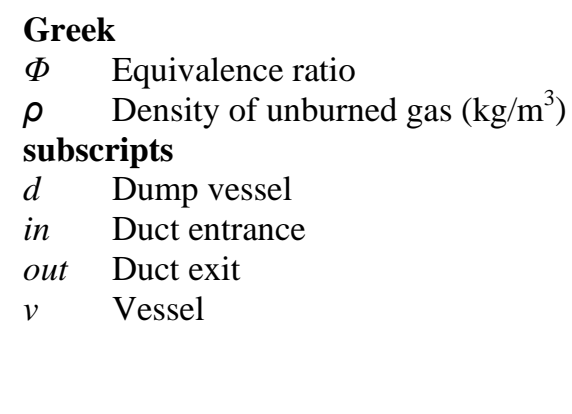

\section{INTRODUCTION}

Venting devices are common practice in industry to lessen the potential damage caused by internal gas and dust explosions. Venting is both economical and practical which makes it a very attractive prospect to industrial applications.

When flames and pressure waves emerging from the vent could pose a hazard, or the material being discharged is toxic then it is necessary to fit explosion vents with discharge ducts to direct the vented material from the enclosure to a safe location [1]. The presence of the duct, however, results in an enhancement of the explosion severity in 
comparison to simply vented vessels [2,3]. This can lead to an increase in maximum overpressure by a factor of ten or more [4].

Furthermore, the presence of the duct has been reported to shorten the distance for deflagration to detonation transition [5]; for very reactive systems, short ducts (using a 4-1 test vessel with vent $\mathrm{L} / \mathrm{D}$ ratio of up to 6 ) have been observed to be responsible for the onset of upstream directed detonation in the main vessel [6].

The study of an explosion vented through a duct is therefore of great relevance to safety issues and consequently has received considerable attention in literature. Some experimental works have focused on the effect of the duct length and diameter upon explosion overpressure, allowing some trends to be drawn $[4,7,8]$.

Other work has focused on the effect of traditionally fundamental parameters in simply vented explosions such as the ignition position, initial turbulence and pressure of vent deployment [4,9]; a particular point raised in this work is that central ignition is addressed as the worst case. This is in agreement with the general trend observed in literature for simply vented vessels. The cited works of Ponizy and Leyer and later of Ponizy and Veyssiere [10] are prominent as they represent a most comprehensive set of experimental data for this venting configuration and give a big contribution to the understanding of the phenomenon. These works are based on a small $3.6 \mathrm{l}$ vessel and it is not possible to know if the findings at this small scale are applicable to larger more industrially relevant scales given the well known importance and difficulties of scale effects in explosion dynamics [11,12,13].

To the authors' knowledge, no experimental work has been carried out on the effect of ignition position on a scale larger than the one adopted by Ponizy and Leyer for this venting configuration.

In addition, the effect of the mixture reactivity has not received consideration in the literature, but constitutes an important parameter in the investigation of vented vessel explosions.

In this paper some new experimental data are presented for premixed propane/air explosions in a $200 \mathrm{l}\left(0.2 \mathrm{~m}^{3}\right)$ primary vessel vented through a relief duct. A range of equivalence ratios is investigated for two different ignition positions (rear and central).

The results show that there are no significant differences in values of maximum pressure relative to the rear and central case. Nevertheless, rear case ignition consistently exhibits a much higher rate of pressure rise than the central and should therefore be considered to be the worst case.

\section{EXPERIMENTAL DETAILS}

The configuration used consists of a cylindrical $0.2 \mathrm{~m}^{3}$ vessel $(\mathrm{L}=1.0 \mathrm{~m}, \mathrm{D}=0.5 \mathrm{~m})$ connected to a large dump volume $\left(\sim 50 \mathrm{~m}^{3}\right)$, through a gate valve $(\mathrm{D}=0.162 \mathrm{~m})$ and vent pipe $(\mathrm{L}=1.0 \mathrm{~m}, \mathrm{D}=0.162)$. For the purpose of this research, the dump volume was sufficient to allow these results to be applicable to an explosion vented out into the atmosphere (see Fig. 1).

Measurements of flame-speed were recorded from the primary vessel and duct using an array of exposed junction, mineral insulated, type-k thermocouples, positioned along the centre line. Flame-speed data were generated from thermocouple flame arrival times (marked as an abrupt change in the thermocouple output). The thermocouple flame 
arrival time in the primary vessel was taken to be the first point at which the reading started to rise. For the thermocouples in the duct, this was hindered by a pre-compression wave ahead of the flame (and the associated high flow velocity around the thermocouple) giving rise to two distinct gradients on the thermocouple trace. In this case, the point at which the second (steeper) gradient became apparent was taken as the flame arrival time. The timing of the flame arrival at this location was confirmed with the use of a UV detector in a representative portion of tests, which detected the passage of the flame, and was not influenced by pre-compression and velocity effects. Pressure within the vessel was monitored using an array of piezoresistive pressure transducers at points around the outer wall in each section. The data generated was collected using a 34 channel transient data recorder.

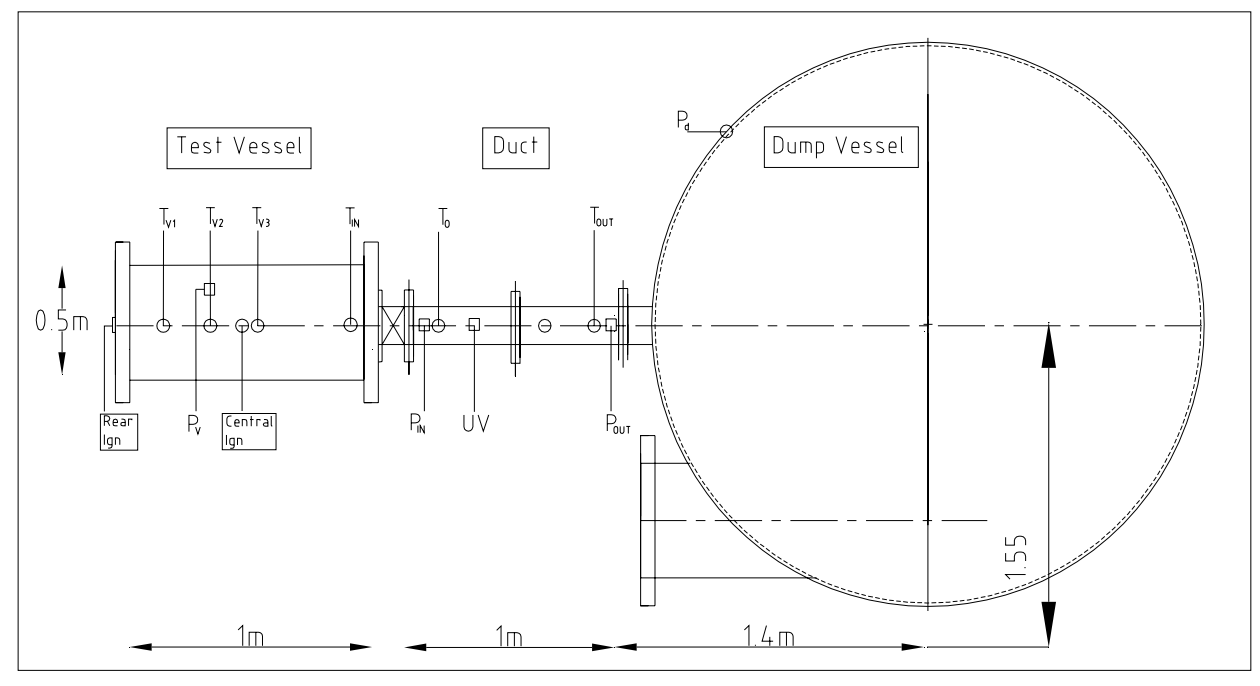

Fig. 1. Vessel geometry.

Ignition was achieved in the primary vessel using a standard 16J combustion engine spark plug of modified length. Ignition was positioned at the rear wall and central to the vessel, each along the centre line opposite the entrance to the duct.

A range of propane gas concentrations were investigated during this test series, ranging from $3.2 \%$ to $6.5 \%$ by volume $(\Phi=0.8-1.6)$, for both rear and central ignition tests. Mixture preparation in this vessel was achieved by partial pressures in the primary vessel only, isolating the primary vessel at the connection between the vessel and the duct using the gate valve. Homogeneity of the mixture was confirmed using gas chromatography. Ignition from one of the two positions was then initiated immediately after opening the gate valve.

Each test was performed three or more times to check for consistency and repeatability of the data. In general this was good but rich mixtures centrally ignited exhibited surprisingly wide variability. These issues will be discussed later in the paper. 


\section{RESULTS AND DISCUSSION}

\section{General Features}

Figure 2 shows the explosion development for a stoichiometric propane-air mixture (4\% $\mathrm{v} / \mathrm{v}$ ) with (a) central ignition and (b) rear ignition in terms of pressure history (at various points in the system) and in terms of the flame position with time along the main vessel and through the vent duct. Time 0 indicates the ignition time at flame position 0 (i.e., at the spark). The times of entry and exit of the flame in the vent duct (tin and tout) as recorded by thermocouples $\mathrm{T}_{\mathrm{IN}}$ and $\mathrm{T}_{\text {OUT }}$ (in Fig. 1), are also marked on Fig. 2.

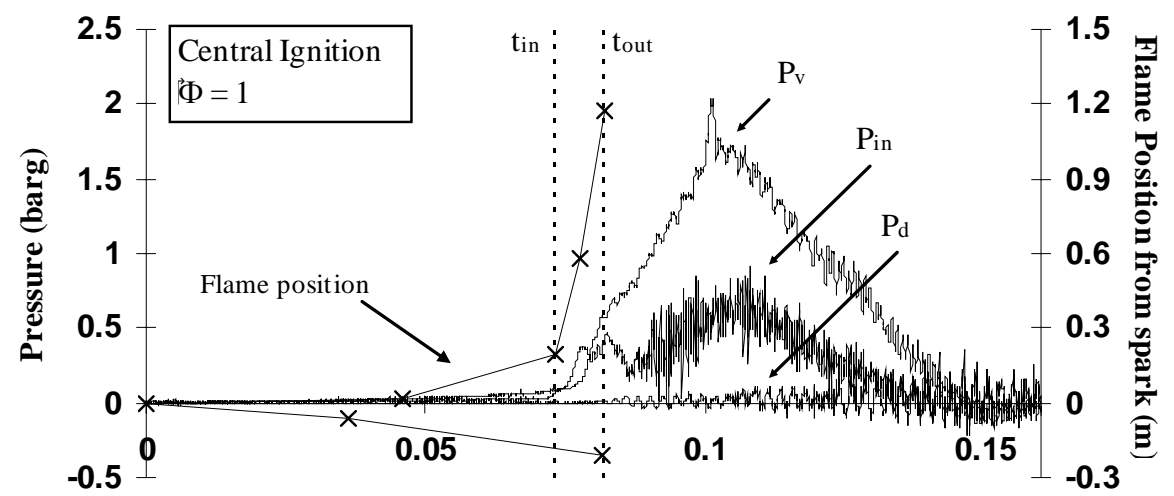

Time (s)

(a)

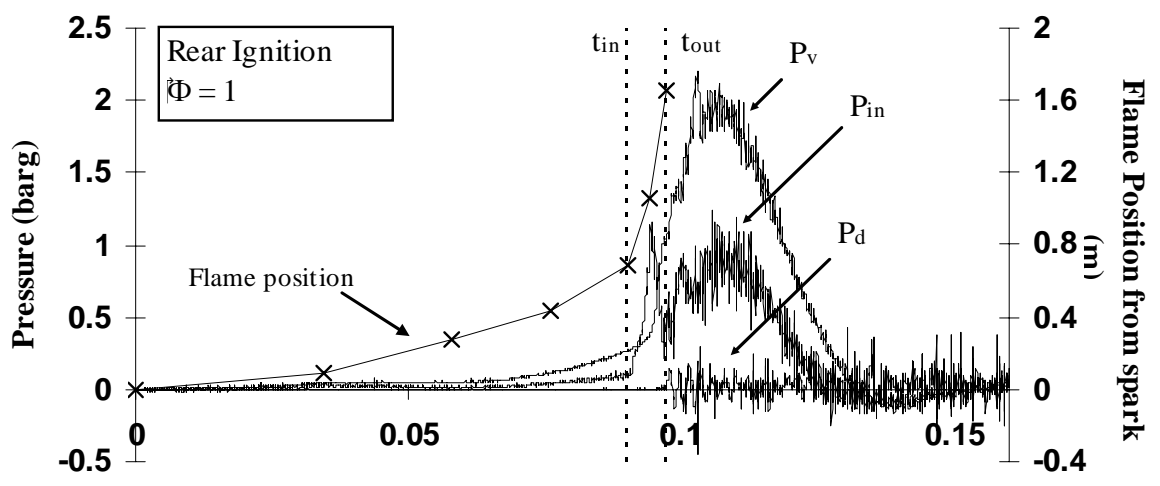

Time (s)

(b)

Fig. 2. Pressures and flame position with time through the test geometry (a) central ignition (b) rear ignition.

In Fig. 2, two different phases of flame propagation are seen for both the rear and central ignition tests; a slow phase with low pressures and low flame propagation rates prior to the flame entering the duct, and a fast phase associated with fast flame speeds through the venting duct and fast changes in pressure. For both ignition positions, the fast rise in pressure (albeit at somewhat reduced rate) continues after the flame exits the duct 
indicating continued strong combustion in the test vessel until a maximum pressure is reached marking the end of the main combustion phase, and the pressure decays thereafter as continued outflow through the vent (and system heat-loss) brings the pressure back down to ambient levels.

\section{Flow and Combustion Dynamics}

Up to the time of flame entry into the duct $\left(t_{\mathrm{in}}\right)$, a slow increasing pressure in the test vessel $\left(\mathrm{P}_{\mathrm{v}}\right)$ establishes a positive pressure gradient between the vessel and the duct indicating an outflow from the vessel to the duct, which is relieving the build-up of pressure from the combustion in the vessel. This pressure difference reaches a maximum just prior to the flame entry in the tube and this is more pronounced in the case of rear ignition. It will be shown that this pressure difference initiates a sequence of flow/combustion interactions that determine the severity of the subsequent explosion development. A direct correlation will be shown between the velocity of the flow induced by this pressure gradient and the maximum rate of pressure rise (effectively the maximum rate of burning) measured in these tests.

From the pressure records taken along the test rig at the monitoring positions marked in Fig. 1, it was possible to derive the pressure differences induced between these points at various times of interest during the explosion. Examples of such pressure differences are shown in Fig. 3, for the same rear ignition test as in Fig 2(b), for the time interval when the flame was travelling along the vent duct.

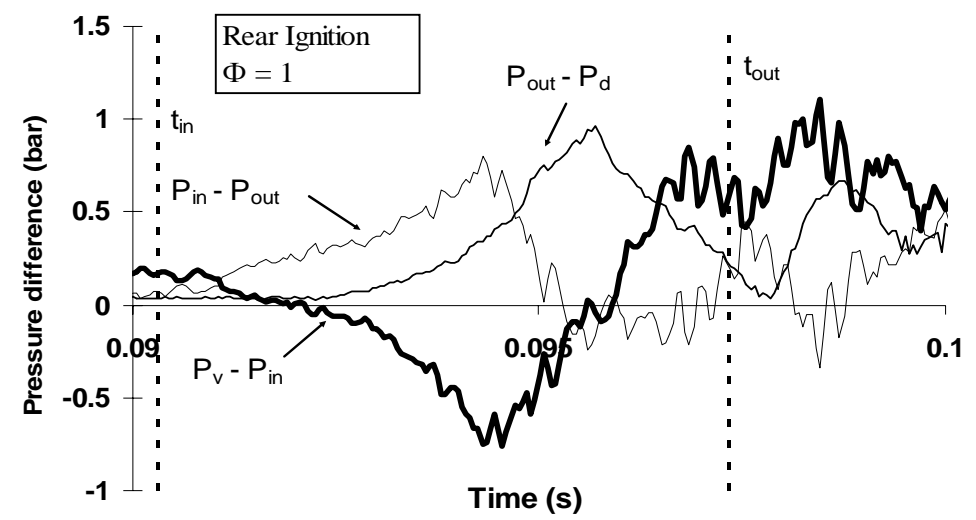

Fig. 3. Pressure differences at selected positions along the test rig during the period of the flame travel through the duct.

The expansion of the hot gases, following ignition and flame propagation in the main vessel, generates a flow field in the unburned gases ahead of the flame and into the vent duct. The sudden flow contraction at the duct entrance induces a flow separation from the surface of the duct wall and the formation of shear layers. A few diameters downstream of the vena contracta, the turbulent flow field reattaches to the duct wall. This flow pattern is associated with flow pressure (energy) losses which are characteristic of the geometry, and expressed in terms of the pressure loss coefficient $\mathrm{K}$, given by

$K=\frac{\Delta P}{\frac{1}{2} \rho u^{2}}$ 
The pressure loss $\Delta \mathrm{P}$ is measured between the main vessel and a point downstream of the disturbance. In the present case this would roughly correspond to the difference between $P_{v}$ and $P_{i n}$ marked as $\left(P_{v}-P_{i n}\right)$ in Fig. 3. The maximum value of this difference relating to the induced unburned gas flow was measured just prior to the flame entry, i.e., to the left of the " $\mathrm{t}_{\mathrm{in}}$ " dashed line in Fig. 2. For this example this pressure difference is shown to be of the order of 170 mbar.

The entry pressure loss coefficient is fairly constant (characteristic for the geometry) and for a large vessel to duct ratio (as in the present case) it is of the order of 0.5. Substituting this and the $\left(\mathrm{P}_{\mathrm{v}}-\mathrm{P}_{\text {in }}\right)$ measurement of 170 mbar into Eq. 1 using a density $\rho$ of $1.2 \mathrm{~kg} / \mathrm{m}^{3}$ (ignoring any small pressure rise and any compressibility effects) we get an unburnt gas flow velocity in the duct of around $240 \mathrm{~m} / \mathrm{s}$. This a very large flow velocity even allowing for a generous margin of error of say $20 \%$ for the incompressibility assumption, and it will generate a very turbulent flow field within the duct.

When the flame enters the duct, after having been severely stretched in the contraction region, it encounters the strong turbulence field that promotes intense mixing of cold and hot gases leading to a subsequent violent combustion, which is the cause of the abrupt pressure rise on signal $P_{\text {in }}$ shown in Fig. 2. This strong combustion in the duct results in massive reversal of the pressure towards the test vessel $\left(\mathrm{P}_{\mathrm{v}}-\mathrm{P}_{\text {in }} \approx-0.7\right.$ bar) and in an even bigger push (around 1 bar) along the duct and out into the dump vessel (see Fig. 3 - (Pin$\left.\mathrm{P}_{\text {out }}\right)$ and $\left(\mathrm{P}_{\text {out }}-\mathrm{P}_{\mathrm{d}}\right)$ ). Effectively this violent event somewhere around the middle of the duct, pushes a strong flow away from the region in both directions upstream and downstream. This is a short duration event (less than $5 \mathrm{~ms}$ in this case) but it has a dramatic effect on the combustion taking place in the main vessel: it hinders (stops, reverses) the gas release from the main vessel and at the same time it increases the combustion rate by promoting increased turbulence (by the physical back-flow into the vessel) and by the interaction of the shock/pressure waves with the flame frame. These influences manifest as the rapid pressure rise in the test vessel as shown by $\mathrm{P}_{\mathrm{v}}$ in Fig. 2(b). Similar effects have also been described by others $(3,4)$.

For a fixed duct-vessel area ratio, the dynamic of the flame in the initial sections of the duct is ruled from its velocity upstream of the constriction (i.e., in the vessel). In turn the flame speed in the last sections of the vessel depends on both the ignition position and the strength of the mixture. In particular, ignition points far from the duct entry and more reactive fuels, are expected to give the highest flame speeds in the vessel and the strongest turbulent fields in the initial sections of the duct. The effect of ignition position is illustrated in Fig. 2, where it is shown that although the rear ignition test is initially slower once the flame enters the vent duct, the increase in pressure in the main vessel is then much faster than the central ignition case. This has also been observed on a small scale by Iida et al. [14]. Moreover, Ponizy and Leyer [9] performed a study of the effect of the ignition position on the final overpressure in the vessel. One of the important findings of that study was that even if the rear ignition gives rise to a more violent explosion in the duct and higher rates of pressure rise in the vessel, the central ignition eventually caused the higher final pressure in the vessel. Any direct quantitative relationship between the violence of the explosion in the duct and the violence of the explosion in the main vessel was then ruled out. As noted in the introduction, the work of Ponizy and Leyer was carried out in a small scale vessel (3.6 l) and the clear need arises of assessing those findings on a larger scale. 
The oscillatory peaks observed shortly after the flame has left the duct, could be related to the backward propagating train of compression waves created by the strongly unsteady flame propagation in the duct [4,5]. Similar pressure traces in the main vessel and in the relief duct have been observed for the same venting configurations on both smaller scales and larger scales $[3,8,9]$.

In particular the sudden energy release necessary to generate the shock wave in the duct is to be linked to a secondary explosion in the initial sections of the duct $[2,3,4]$ and is sometimes referred to in literature as burn-up. Burn-up in the duct has then to be considered a crucial phenomenon affecting the final overpressure of the vessel. As long as the importance of this secondary explosion is recognized, attention is to be drawn to parameters affecting it.

\section{Flame Speeds}

From the previous discussion it is suggested that the induced flow through the duct plays a most important role in the final severity of the explosion. This flow is driven by the flame expansion and propagation in the main vessel.

Figure 4 reports the average flame speeds measured in second half of the main vessel (between $T_{v 3}$ and $T_{i n}$ in Fig. 1) and the average flame speeds in the vent duct (between $T_{0}$ and $\mathrm{T}_{\mathrm{OUT}}$ in Fig. 1), as a function of propane concentration and for the different ignition positions.

For central ignition the main vessel flame speeds ranged 5 to $10 \mathrm{~m} / \mathrm{s}$ with the maximum value on the rich side (4.5\%) of stoichiometric. With rear ignition the flame speeds in the main vessel were significantly higher (up to 5 times) than for central ignition and exhibited stronger dependence on the concentration ranging from 15 to $20 \mathrm{~m} / \mathrm{s}$ for lean and reach mixtures and up to $50 \mathrm{~m} / \mathrm{s}$ for the slightly rich $4.5 \%$ mixture.

The faster flame speeds with the rear ignition can be explained by the fact that the burnt gases are only allowed to expand in one direction resulting in an elongated flame with increasing larger surface area (reaction front) and hence faster expansion than the centrally ignited flames.

On the basis of the above, the rear ignition tests would be expected to produce higher flows in the duct and hence more severe duct explosions which would feed back as more severe explosions in the main vessel. The measured flame speeds in the duct shown in Fig. 4b do not reflect the big differences of the upstream flame speeds for the different ignition positions. It was difficult to measure these very fast duct flame speeds accurately. In the tests we had used more thermocouples in the duct than the two reported here but the flame was "seen" to arrive at several thermocouples at once and/or out of sequence in terms of the expected direction of flame propagation, which made a more detailed analysis of the flame speed within the duct impossible. A possible explanation for these phenomena would be that at the very high turbulence levels in the duct, turbulent flame quenching causes irregular propagation within the duct and puts an upper limit on the flame propagation rate. The high flame speeds measured in the duct are comparable to those measured in the initial sections of the much greater relative length (larger L/D) by Ponizy and Leyer [4] who reported continued flame acceleration along the duct. 


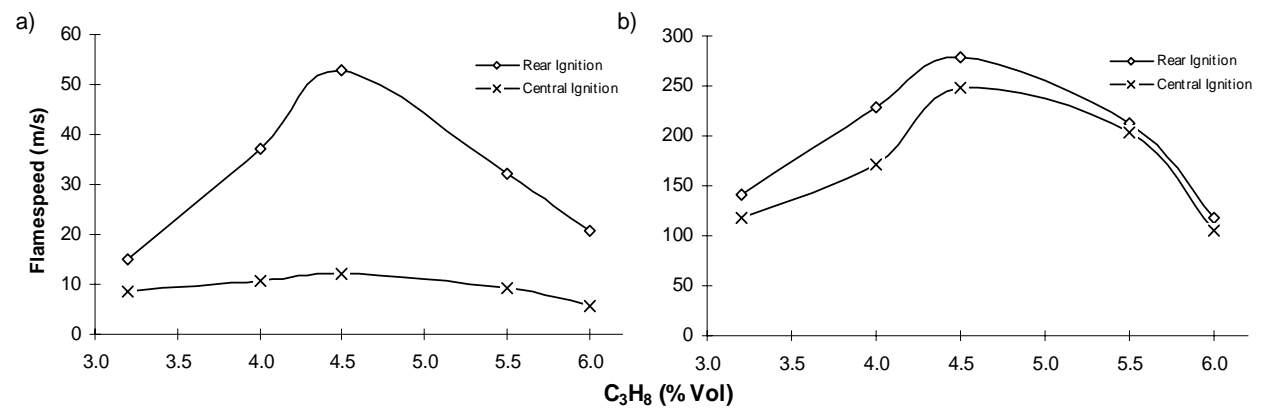

Fig. 4. Average flame speeds measured (a) in second half of the main vessel (between $\mathrm{T}_{\mathrm{v} 3}$ and $\mathrm{T}_{\mathrm{in}}$ in Fig. 1) and (b) in the vent duct (between $\mathrm{T}_{0}$ and $\mathrm{T}_{\mathrm{OUT}}$ in Fig. 1), as a function of propane concentration and for the different ignition positions.

In Fig 5 the same flame speeds are normalised by dividing with the laminar burning velocity (values derived using expression from ref [15]).

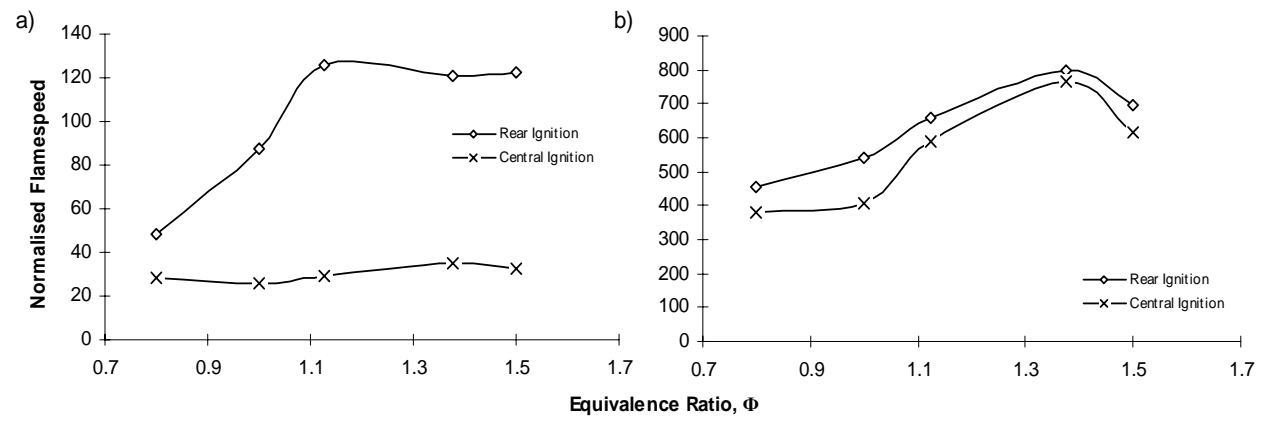

Fig. 5. Flame speeds presented in Fig. 4 normalised by the laminar burning velocity and plotted against the equivalence ratio.

This normalisation produces an "effective" expansion factor. For a laminar spherical explosion this would be equal to the unburned to burned gas density ratio, typically around 8 for most hydrocarbons (for stoichiometric adiabatic combustion) and would be lower for mixtures on either side of the stoichiometric. For the tests shown in Fig. 5(a), the effective expansion factor was much higher than 8, of the order of 30 for central ignition (i.e., about 4 times higher than for spherical laminar) and up to circa 130 (or 16 times higher than for spherical laminar) for rear ignition. The effective expansion factor is directly related to the burning rate which is a function of both the flame area (reaction front) and the burning velocity. Since the mixtures were quiescent when ignited and since there were no turbulence inducers in the early stages of propagation, then it would be expected that the burning would have been near the laminar value for both cases. Therefore the differences in the flame speeds shown must be due to bulk flame area distortion effects. In both cases the flame will accelerate towards the vent and in the case of the central ignition this will result in an initially spherical flame, progressively being stretched on one side towards the vent. In the case of rear ignition an initially hemispherical flame front (anchored on the ignition wall) will also progressively stretch towards the vent but this will result in a long cylindrical flame which the data suggest had a much larger flame area than the central ignition flame. 
This may explain the different results for the two ignition positions. For a given ignition position the flame shape would be similar for all mixture concentrations and hence the flame speeds would be expected to reduce either side of stoichiometric in accordance with the laminar burning velocity. This is not supported by the measurements witch show that in relative terms the flame speeds recorded by the fuel rich mixtures are comparable to those at near stoichiometric. Rich mixtures are known to be more susceptible to developing surface instabilities (flame cellularity) which would lead to higher burning rates and hence higher flame speeds and this in turn could result in a more severe vented explosion than might be expected (on the basis of its laminar burning velocity alone).

The onset of cellularity is also dependent on the flame size with larger flames being more likely to develop this behaviour. Therefore, the effects of cellularity may also be contributing to the faster flame speeds measured in the main vessel with rear ignition reported in Fig.4 (in addition to the bulk flame area effects). A flame developing from a rear ignition it has more room to grow larger and thus become (more) cellular.

\section{Maximum Pressures and Rates of Pressure Rise}

The maximum explosion pressures measured in all tests performed in this investigation are given in Fig. 6 as a function of the equivalence ratio. In this figure we included all the repeat tests at each condition in order to give an indication to the reader of the test to test variability of the results. It is evident that centrally ignited mixtures exhibited much greater variability than those ignited at the rear of the vessel and this was more pronounced for rich mixtures. The reasons for this behaviour are unclear but these tests appear to be characterised by two distinct modes of burning one producing higher overpressures than the other. This is currently under investigation (and beyond the scope of this paper).

In the explosion literature and practice it is generally assumed that central ignition within an enclosure will produce worst case explosions. Empirical correlations for explosion protection are generally based on experimental data from centrally ignited tests. The data in Fig. 6 show that in terms of average maximum pressures the two ignition positions produced similar results and therefore neither can be characterised as worse than the other.

For the current tests the maximum rates of pressure rise in the main vessel were those measured immediately after the flame entry rapid combustion in the duct. As discussed earlier this caused a major disturbance in the vessel through back-flow, pressure wave interaction with the flame and hindering (or stopping) the venting process.

The rate of pressure rise data appear more repeatable than the maximum overpressure results and show that rear ignition produced a more severe explosion for all mixtures tested. The rate of pressure rise is a much more important yardstick of explosion severity as any explosion protection system (venting or suppression) has to cope with the maximum rate of burning and maximum rate of pressure generation. For example a vent has to be sufficiently large to release gases at the rate needed to balance the rate of pressure rise. Additionally in the case of covered vents (not as in the present tests) there will be an opening/breaking inertia of the vent and this delay will have greater consequences in a faster rising pressure explosion than in slower one. 


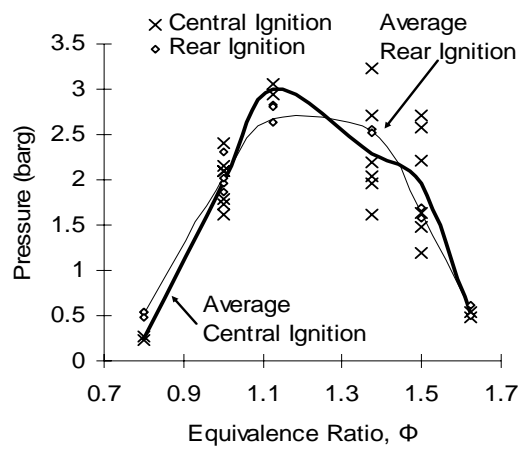

Fig. 6. Maximum pressures in the vessel as a function of fuel equivalence ratio.

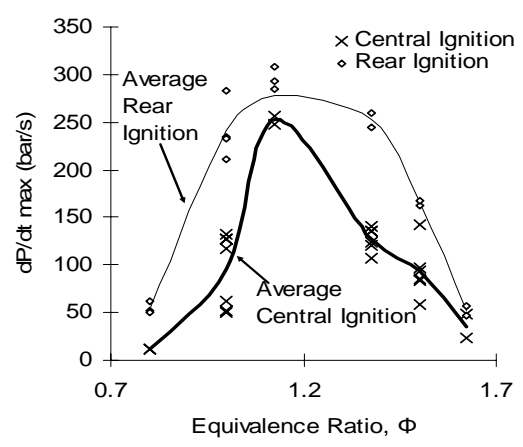

Fig. 7. Maximum rates of pressure rise as a function of the fuel equivalence ratio.

In a vented explosion the maximum pressure is a function (among other factors) of the maximum burning rate but also of the amount of fuel that is consumed at that rate. In the present experiments the rear ignition would have consumed and pushed out more of the mixture (than the central ignition tests) before the fast burning phase and therefore there would have been less fuel left to burn during the fast burning phase.

\section{PRACTICAL IMPLICATIONS / CONCLUSIONS}

It has been shown that the most severe phase of the explosion in the main vessel follows the violent explosion in the duct. It was also suggested that the severity of the ductexplosion itself is determined by the flame propagation in the main vessel prior to entering the duct. A characteristic and fairly accurately quantifiable measure of the latter is the is the flow velocity induced in the duct just prior to the flame entry as derived by Eq. 1, based on the measurement of the pressure difference $\left(\mathrm{P}_{\mathrm{v}}-\mathrm{P}_{\text {in }}\right)$ just prior to the duct flame entry (just to the left of the dashed line marked $t_{i n}$ in Fig. 3, and using the methodology and assumptions discussed earlier.

Figure 8 shows that there is a direct correlation between the maximum rate of pressure rise in the main vessel and the induced velocity in the duct prior to the flame entry. The correlation of the rear ignition data is remarkably good (99\%), while the central ignition in agreement with the previous discussion showed significant scatter causing a reduction of the correlation to a statistically inconclusive $52 \%$. The two ignition conditions would be expected to produce different constants in the correlation because of different vessel conditions (in particular different amounts of remaining unburned mass in the vessel) at the time of maximum burning, but the correlation coefficient would be expected to be similar. 


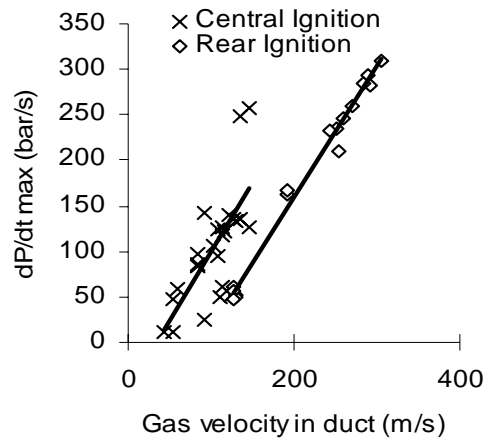

Fig. 8. Maximum rate of pressure rise in the main vessel as a function of the induced velocity in the duct prior to the flame entry.

In terms of relating the major findings of this work to the implications to practical systems with ducted vents the following list is drawn up.

\begin{tabular}{|c|c|c|}
\hline Finding & What could make it better: & $\begin{array}{l}\text { What could make it } \\
\text { worse: }\end{array}$ \\
\hline $\begin{array}{l}\text { Centrally ignited } \\
\text { explosions do not offer } \\
\text { the worst case. Ignition } \\
\text { remote from the vent } \\
\text { causes higher induced } \\
\text { velocities through the } \\
\text { duct and a more severe } \\
\text { explosion overall. }\end{array}$ & $\begin{array}{l}\text { Provision of additional vents so } \\
\text { that possible ignition locations } \\
\text { are located near vents. This may } \\
\text { have the additional effect that } \\
\text { venting in two directions may } \\
\text { reduce the expansion drive } \\
\text { behind the flame front and } \\
\text { hence the induced velocities in } \\
\text { the vent ducts. }\end{array}$ & $\begin{array}{l}\text { Any obstructions in the } \\
\text { path of the flame in the } \\
\text { main vessel (such as } \\
\text { process equipment) } \\
\text { would result in } \\
\text { acceleration of the } \\
\text { induced flow in the duct. }\end{array}$ \\
\hline $\begin{array}{l}\text { The pressure losses in } \\
\text { ducted vents including } \\
\text { entry, duct-friction and } \\
\text { exit losses }\left[\left(\mathrm{P}_{\mathrm{v}}-\mathrm{P}_{\text {in }}\right)\right. \\
\left(\mathrm{P}_{\mathrm{in}}-\mathrm{P}_{\text {out }}\right) \text { and }\left(\mathrm{P}_{\text {out }}-\mathrm{P}_{\mathrm{d}}\right) \\
\text { in Fig. } 2 \text { respectively] } \\
\text { are all contributing to } \\
\text { the explosion severity. }\end{array}$ & $\begin{array}{l}\text { These should be minimised with } \\
\text { more aerodynamic design, } \\
\text { gradual contraction and } \\
\text { expansion, shorter straight duct } \\
\text { lengths. These may introduce } \\
\text { high costs in retrofit } \\
\text { applications but in new designs } \\
\text { additional costs would be } \\
\text { marginal. }\end{array}$ & $\begin{array}{l}\text { Sharp entry and exit } \\
\text { points, obstructions in } \\
\text { the vent duct, bends and } \\
\text { changes in cross section } \\
\text { could all increase the } \\
\text { final system } \\
\text { overpressure. }\end{array}$ \\
\hline $\begin{array}{l}\text { The duct explosion } \\
\text { following entry of the } \\
\text { flame in the duct } \\
\text { severely diminishes the } \\
\text { effectiveness of the } \\
\text { vent and turbulises the } \\
\text { mixture in the main } \\
\text { vessel }\end{array}$ & $\begin{array}{l}\text { Suppression of the duct } \\
\text { explosion either by using } \\
\text { chemical suppression or a flame } \\
\text { arrester in the duct entry region } \\
\text { may prove an effective } \\
\text { approach not withstanding any } \\
\text { economic considerations. }\end{array}$ & $\begin{array}{l}\text { Any turbulence inducing } \\
\text { devices at the duct entry } \\
\text { region will accelerate the } \\
\text { flame and cause a more } \\
\text { severe duct explosion } \\
\text { which would feed back } \\
\text { into the main vessel }\end{array}$ \\
\hline
\end{tabular}

\section{ACKNOWLEDGEMENTS}

Our thanks to EPSRC for the PhD Studentship to S. Willacy, and the Instituto di Ricerche Sulla Combustione for their support to G. Ferrara during his research visit at Leeds. 


\section{REFERENCES}

[1] NFPA 68, "Guide for Venting of Deflagration,” National Fire Protection Association, Quincy, 2002.

[2] Bartknecht, W., Explosions, Course Prevention Protection, Springer-Verlag, Berlin, 1981.

[3] Molkov, V.V., "Venting of Deflagrations: Dynamic of the Process in Systems with a Duct and Receiver," Proceedings of the Fourth International Symposium on Fire Safety Science, 1994, pp. 1245-1254.

[4] Ponizy, B., and Leyer, J.C., "Flame Dynamics in a Vented Vessel Connected to a Duct: 1. Mechanism of Vessel-duct Interaction,” Combustion and Flame, 116, pp. 259-271, (1999a).

[5] Bouhard, F., Veyssiere, B., and Leyer, J., "Explosion in a Vented Vessel Connected to a Duct," Progress in Astronautics and Aeronautics, 134, p. 85, (1991).

[6] Medvedev, S.P., Polenov, A.N., Khomik, S.V., and Gelfand, B.E., "Initiation of Upstream Directed Detonations Induced by the Venting of Gaseous Explosions,” 25th Symposium (International) on Combustion, 1994, pp. 73-78.

[7] Wiekema, B.J., Pasman, H.J., Groothuizen, Th.M., "The Effect of Tubes Connected with Pressure Relief Vents," $2^{\text {nd }}$ International Symposium on Loss Prevention and Safety Promotion in the Process Industries, 1977, pp. 223-231.

[8] Kordylewski, W., and Wach, J., "Influence of Ducting on Explosion Pressure: Small Scale Experiments,” Combustion and Flame, 71, pp. 51-56, (1988).

[9] Ponizy, B., and Leyer, J.C., "Flame Dynamics in a Vented Vessel Connected to a Duct: 2. Influence of Ignition Site, Membrane Rupture, and Turbulence," Combustion and Flame, 116, pp. 272-281, (1999b).

[10] Ponizy, B., and Veyssiere, B., "Mitigation of Explosions in a Vented Vessel Connected to a Duct," Combustion, Science and Technology, 158, pp. 167-182, (2000).

[11] Solberg, D.M., Pappas, J.A., and Skramstad, E., "Observation of Flame Instabilities in Large Scale Vented Gas Explosions”, 18th Symposium (International) on Combustion, The Combustion Institute, 1981, pp. 1607-1614.

[12] Phylaktou, H., and Andrews, G.E., "Application of Turbulent Combustion Models to Explosion Scaling,” Trans IChemE, 73, Part B: pp. 3-10, (1995).

[13] Molkov, V.V., Dobashi, R., Suzuki, M., and Hirano, T., "Venting of Deflagrations: Hydrocarbon-air and Hydrogen-air Systems," Journal of Loss Prevention in the Process Industries, 13, pp.397-409, (2000).

[14] Iida, N., Kawaguchi, O., and Takeshi, S., "Premixed Flame Propagating into a Narrow Channel at a High Speed, Part 1: Flame Behaviors in the Channel," Combustion and Flame, 60, pp. 245-255, (1985).

[15] Abu-Orf, G.M., Cant, R.S., "A Turbulent Reaction Rate Model for Premixed Turbulent Combustion in Spark-ignition Engines," Combustion and Flame, 122, pp. 233-252, (2000). 